\title{
Appareil
}

$22 \mid 2020$

Une philosophie de l'appareil

\section{Scène inaugurale, Mai 68}

\section{Alain Brossat}

\section{OpenEdition}

Journals

Édition électronique

URL : http://journals.openedition.org/appareil/3598

DOI : 10.4000/appareil.3598

ISSN : 2101-0714

Éditeur

MSH Paris Nord

\section{Référence électronique}

Alain Brossat, « Scène inaugurale, Mai 68 », Appareil [En ligne], 22 | 2020, mis en ligne le 21 décembre 2020, consulté le 26 mars 2021. URL : http://journals.openedition.org/appareil/3598 ; DOI : https:// doi.org/10.4000/appareil.3598

Ce document a été généré automatiquement le 26 mars 2021.

\section{(c) (i) (2) $\Theta$}

Appareil est mis à disposition selon les termes de la Licence Creative Commons Attribution - Pas d'Utilisation Commerciale - Pas de Modification 4.0 International. 


\title{
Scène inaugurale, Mai 68
}

\author{
Alain Brossat
}

La disparition de Jean-Louis a été si soudaine et si brutale qu'il m'est bien difficile de trouver les mots pour en parler. Quoi de plus difficile que d'enchaîner un discours sur un événement qui nous sidère et nous met en pièces ? - aurait dit Jean-Louis, peut-être...

Dans tout ce que nous avons tenté d'animer ensemble, ou que nous avons traversé, tous ces séminaires, ces colloques, ces universités d'été, à Paris 8 et à la Maison des Sciences de l'Homme Paris Nord, mais aussi hors les murs, en France ou à l'étranger - dans tout ceci, il y avait toujours quelque chose qui venait en supplément de notre charge d'enseignement ou de nos obligations de recherche, qui y demeurait irréductible - une forme de connivence dans nos différences et nos divergences mêmes, un effet de l'amitié qui rendait les choses tellement plus faciles et le métier plus attrayant.

2 Ce n'est un secret pour personne que ce département de philosophie de Paris 8, qui était notre port d'attache, n'était pas tous les jours une abbaye de Thélème et notre proximité n'y fut pas, au fil des années, d'un médiocre secours lorsqu'il s'agit d'y affronter, disons, la gamme complète des intempéries qui y sévissaient. De même, je n'aurai garde d'oublier ce qui, pour lui comme pour moi, passait de loin avant le souci de l'enseignement magistral : les interactions complices avec les étudiants, qui, au fil des ans, suscitèrent parfois, souvent, de solides amitiés. Point limite de l'enseignement où ce dernier cède le pas à la communauté.

3 Lorsque j'étais étudiant à Nanterre, en 1967-1968, le seul cours que je suivais très régulièrement n'était pas le cours d'amphithéâtre de Paul Ricœur, ni celui d'Henri Lefebvre, c'était une sorte de TD [travaux dirigés] animés par JeanFrançois Lyotard, pas encore tout à fait prof en titre à l'époque et qui achevait, durant ces années-là, de fendre son armure phénoménologique. Ces cours, à l'occasion desquels Lyotard explorait ses nouvelles voies, me fascinaient. Et, parmi les étudiants en licence de philosophie qui les peuplaient, dont la grande majorité alla rejoindre les rangs du 22 mars et des différents groupes maos, trotskos, anars, etc., se tenant un peu à l'écart des autres, toujours au premier rang, il y avait ce binoclard que l'on ne retrouvait guère dans les AG [assemblée générale], qui ne partageait pas nos codes gauchistes mais qui, régulièrement, raflait les meilleures notes aux dissertations et 
avait, à la fin des cours, de longs conciliabules avec le maître. Ce type qui m'intriguait autant qu'il m'irritait, je suis sûr que c'était Jean-Louis - mais la chose étrange, c'est que pendant toutes les années de notre compagnonnage à Paris 8 , je n'ai jamais tenté d'en avoir le cœur net... J'avais cette image qui me trottait dans la tête, parmi d'autres souvenirs de ces années magiques, et je n'avais pas le désir d'en ternir l'aura en la branchant directement sur ce présent parfois un peu grisâtre où notre tour était venu d'occuper la place de Lyotard - notre aîné à Paris 8.

Et c'est ainsi qu'au terme de ce long parcours accidenté, l'image et le souvenir «originaires» de Jean-Louis demeurent associés, par un biais plutôt bizarre et contourné, à ce qui n'a jamais cessé d'être pour moi le point d'orientation, l'étoile du Midi : l'année 1968, Mai 68 et ses prémices à l'université de Nanterre... Ce Jean-Louis que je voyais de dos, buvant les paroles de Lyotard et déjà philosophe alors que je me voyais bien plutôt en révolutionnaire à vie, ce Jean-Louis-là, l'ai-je inventé ? N'est-il qu'un faux souvenir de plus ou bien était-il vraiment là en chair et en os ? Qu'importe, au fond: s'il est une chose que nous avions en commun, avec toutes nos dissensions, voire nos différends, c'est Walter Benjamin et tout le monde de la fantasmagorie. J'aime à me dire, sur le lieu de cette séparation qui m'a pris au dépourvu et m'a glacé, que de la plus douce de mes fantasmagories, celles de Mai 68 et de sa scène inaugurale, tu demeures, cher Jean-Louis, inséparable.

\section{RÉSUMÉS}

Le texte se souvient du contexte philosophique, intellectuel et politique dans lequel JeanLouis Déotte et Alain Brossat, futurs collègues à l'université Paris 8 , étudièrent à Nanterre, au printemps 1968.

\section{INDEX}

Mots-clés : Université Paris 8, Maison des Sciences de l'Homme Paris Nord, Nanterre

\section{AUTEURS}

\section{ALAIN BROSSAT}

Research Fellow à l'International Center for Cultural Studies, National Chiao Tung University, Taïwan. 